\title{
$17 \beta$-Estradiol is necessary for extinction of cocaine seeking in female rats
}

\author{
Robert C. Twining, Jennifer J. Tuscher, Elizabeth M. Doncheck, Karyn M. Frick, \\ and Devin Mueller ${ }^{1}$
}

Department of Psychology, University of Wisconsin-Milwaukee, Milwaukee, Wisconsin 53211, USA

\begin{abstract}
Human and preclinical models of addiction demonstrate that gonadal hormones modulate acquisition of drug seeking. Little is known, however, about the effects of these hormones on extinction of drug-seeking behavior. Here, we investigated how $17 \beta$-estradiol $\left(E_{2}\right)$ affects expression and extinction of cocaine seeking in female rats. Using a conditioned place preference (CPP) paradigm, ovariectomized rats were maintained throughout conditioning with $2 \mathrm{~d}$ of $\mathrm{E}_{2}$ treatment followed by $2 \mathrm{~d}$ of vehicle treatment, or were injected with $E_{2}$ daily. Hormone injections were paired or explicitly unpaired with place conditioning sessions. Expression of a cocaine CPP was of equal magnitude regardless of conditioning protocol, suggesting that $E_{2}$ levels during conditioning did not affect subsequent $C P P$ expression. During extinction, daily $E_{2}$ administration initially enhanced expression of the cocaine CPP, but resulted in significantly faster extinction compared to controls. Whereas $E_{2}$-treated rats were extinguished within $8 \mathrm{~d}$, vehicle-treated rats maintained CPP expression for more than a month, indicative of perseveration. To determine whether $E_{2}$ could rescue extinction in these rats, half were given daily $E_{2}$ treatment and half were given vehicle. $E_{2}$-treated rats showed rapid extinction, whereas vehicle-treated rats continued to perseverate. These data demonstrate for the first time that $E_{2}$ is necessary for extinction of cocaine seeking in female rats, and that it promotes rapid extinction when administered daily. Clinically, these findings suggest that monitoring and maintaining optimal $E_{2}$ levels during exposure therapy would facilitate therapeutic interventions for female cocaine addicts.
\end{abstract}

Gonadal hormones render women more susceptible than men to developing compulsive patterns of psychostimulant use. Natural fluctuations in levels of the primary ovarian hormones, estrogens and progesterone, account for this increased abuse liability. Higher levels of estrogens, and lower levels of progesterone, are associated with greater sensitivity to the euphorigenic properties of cocaine in women (Evans 2007). This increased sensitivity may contribute to why women, compared with men, start using cocaine regularly at a younger age (Chen and Kandel 2002), transition from use to abuse more quickly (McCance-Katz et al. 1999), experience greater craving in response to drug-associated cues (Robbins et al. 1999) and stress (Potenza et al. 2012; Waldrop et al. 2012), and exhibit more severe drug-seeking behavior upon relapse (Gallop et al. 2007). In contrast, more women than men remain abstinent after treatment (Weiss et al. 1997). Thus, women are both more susceptible to cocaine abuse and, paradoxically, more responsive to treatment.

A substantial literature supports that estrogens mediate the enhancement of drug seeking observed in females (Febo et al. 2002; Larson et al. 2007; Segarra et al. 2010; Kerstetter and Kippin 2011), but little is known regarding the role of estrogens during treatment. Preclinically, treatment is modeled through extinction learning, which results in the formation of a new inhibitory memory that suppresses drug seeking (Quirk and Mueller 2008; Torregrossa and Taylor 2012). Whether estrogens are necessary for extinction of drug seeking, however, remains unknown. Extinction is a form of new learning, and the potent estrogen $17 \beta$-estradiol $\left(\mathrm{E}_{2}\right)$ has been shown to enhance learning and memory across paradigms (Daniel 2006; Frick 2012). For example, $\mathrm{E}_{2}$ enhances the consolidation of object recognition and spatial memory in ovariectomized female rats (Gresack and Frick 2006a) and,

\footnotetext{
${ }^{1}$ Corresponding author

E-mail: devinm@uwm.edu

Article is online at http://www.learnmem.org/cgi/doi/10.1101//m.030304.113.
}

importantly, higher levels of $E_{2}$ in intact female rats and humans are associated with enhanced consolidation and recall of fear extinction (Milad et al. 2009, 2010). Therefore, $\mathrm{E}_{2}$ may be a key mediator of both acquisition and extinction of cocaine seeking in female rats. The effects of $\mathrm{E}_{2}$ on extinction of cocaine seeking in females, however, have not yet been examined.

Here, we assessed the necessity of $\mathrm{E}_{2}$ for extinction of cocaine seeking in female rats. Using a conditioned place preference (CPP) procedure, ovariectomized female rats were administered vehicle or $E_{2}$ during acquisition and extinction. We first determined the effects of $E_{2}$ on expression and extinction of cocaine seeking. We then investigated whether $\mathrm{E}_{2}$ administration would rescue an extinction deficit in perseverating rats. Our results demonstrate that $E_{2}$ is necessary for extinction in female rats, and can facilitate extinction even after long-term perseveration of cocaine seeking.

\section{Results}

Paired $\mathrm{E}_{2}$ during conditioning does not augment cocaine seeking

We first examined the effects of $E_{2}$ during conditioning on the magnitude of cocaine seeking on the first CPP test. To avoid buildup of $\mathrm{E}_{2}$ levels across days, we used a water-soluble form of $\mathrm{E}_{2}$ that is metabolized within $24 \mathrm{~h}$ (Pitha and Pitha 1985). $\mathrm{E}_{2}$ injections $(0.2 \mathrm{mg} / \mathrm{kg}$, i.p.) were either paired (Paired) or explicitly unpaired (Unpaired) with conditioning trials (see Table 1, Experiment 1). After conditioning, rats were given $4 \mathrm{~d}$ with no $E_{2}$ treatment to eliminate carryover effects on the first day of CPP testing (extinction day 1). Both groups were injected with $\mathrm{E}_{2}$ and tested $1 \mathrm{~h}$ later in the absence of cocaine for a cocaine-induced CPP. Both groups exhibited robust and virtually identical cocaine-induced CPPs (Fig. 1A). ANOVA revealed a significant effect of Chamber for both the Paired $\left(F_{(2,20)}=12.64\right.$, $P<0.001)$ and Unpaired groups $\left(F_{(2,22)}=15.02, P<0.001\right)$, but 
Table 1. Timeline and treatment conditions

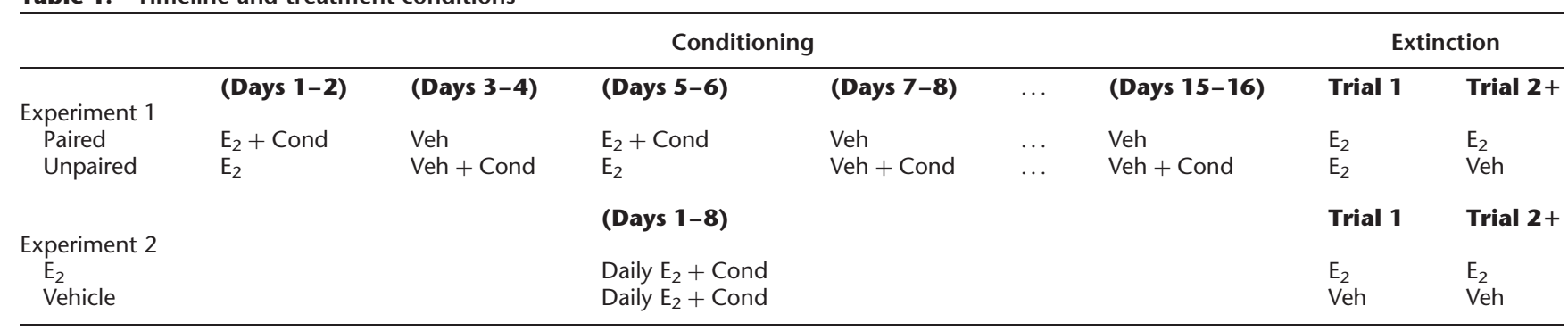

$\left(E_{2}\right) 17 \beta$-estradiol, (Veh) vehicle, (Cond) conditioning.

no Group $\times$ Chamber interaction $\left(F_{(2,42)}=0.54, P=0.59\right)$. Post hoc tests confirmed that both groups spent significantly more time in the cocaine-paired chamber than either the saline-paired or center chambers $\left(P^{\prime} \mathrm{s}<0.05\right)$. Moreover, $\mathrm{E}_{2}$ treatment during conditioning had no effect on motor behavior, as both Paired and Unpaired groups displayed equivalent levels of photobeam breaks during the initial CPP trial $\left(t_{(21)}=1.96, P>0.05\right)$ (Fig. $1 \mathrm{~B})$. Taken together, these data indicate that levels of $\mathrm{E}_{2}$ at the time of conditioning do not affect subsequent cocaine seeking.

\section{$E_{2}$ enhances expression and extinction of cocaine seeking}

To determine the extent to which $\mathrm{E}_{2}$ affects extinction of cocaine seeking, rats received daily injections of vehicle or $\mathrm{E}_{2}$ before each extinction trial. Repeated $\mathrm{E}_{2}$ treatment enhanced expression of the cocaine CPP initially, but promoted rapid extinction relative to vehicle-treated controls (Fig. 2). A mixed model three-way ANOVA (Group $\times$ Chamber $\times$ Extinction Trial) revealed a significant three-way interaction $\left(F_{(28,588)}=1.53, P=0.045\right)$, indicating that $\mathrm{E}_{2}$-treated rats showed a greater CPP magnitude initially but faster extinction than vehicle-treated rats. Post hoc tests confirmed that $\mathrm{E}_{2}$-treated rats exhibited a significantly greater CPP than vehicle-treated rats on trials 4 and $6\left(P^{\prime} \mathrm{s}<0.05\right)$ and a lack of CPP after trial $9(P$ 's $>0.05)$. Vehicle-treated rats, however, exhibited a marked deficit in extinction across trials (Fig. 2), with post hoc tests confirming expression of a CPP through trial $16\left(P^{\prime} \mathrm{s}<0.05\right)$. Furthermore, expression of the CPP continued to persist through trial 25 (data not shown). Taken together, these data suggest that $\mathrm{E}_{2}$ facilitates both expression and extinction of cocaine seeking in female rats and that the absence of $\mathrm{E}_{2}$ prevents extinction.

\section{Acute $\mathrm{E}_{2}$ does not augment cocaine seeking}

Although the magnitude of the initial CPP was not affected by paired or unpaired $E_{2}$ treatment during conditioning, an effect could have been masked because all rats received $\mathrm{E}_{2}$ prior to the first extinction trial. To eliminate the possibility that acute $E_{2}$ affects expression of CPP, two groups of ovariectomized rats were injected daily with $E_{2}(0.2 \mathrm{mg} / \mathrm{kg})$ during conditioning followed by $4 \mathrm{~d}$ with no treatment, and then one group received $\mathrm{E}_{2}$ before the first CPP trial while the other group received vehicle (Table 1 , Experiment 2). Both groups exhibited robust and virtually identical cocaine-induced CPPs (Fig. $3 \mathrm{~A}$ ), indicating that acute $\mathrm{E}_{2}$ injection did not increase expression of a cocaine CPP. Repeated measures ANOVAs revealed a significant effect of Chamber for both groups $\left(\mathrm{E}_{2}, F_{(2,20)}=7.17, P=0.005\right.$; Vehicle, $F_{(2,22)}=8.18$, $P=0.003)$, but no Group $\times$ Chamber interaction $\left(F_{(2,42)}=0.12\right.$, $P=0.88)$. Post hoc tests confirmed that both groups spent significantly more time in the cocaine-paired chamber than in either the saline-paired or center chambers $\left(P^{\prime} \mathrm{s}<0.05\right)$. Moreover, $\mathrm{E}_{2}$ treatment prior to the initial CPP trial had no effect on motor behavior, as both $\mathrm{E}_{2^{-}}$and vehicle-treated groups displayed equivalent amounts of photobeam breaks during the initial CPP trial $\left(t_{(21)}=1.11, P>0.05\right)$ (Fig. 3B). Collectively, these data indicate that the timing of $\mathrm{E}_{2}$ administration during conditioning does not affect CPP magnitude, and that expression of drug seeking does not depend on the acute effects of $E_{2}$ at test.

\section{$E_{2}$ prevents perseverative cocaine seeking}

Although daily $\mathrm{E}_{2}$ treatment during extinction enhanced extinction of drug seeking relative to vehicle treatment, these effects may be altered by the shift from cycling $\mathrm{E}_{2}$ on and off during conditioning to daily $\mathrm{E}_{2}$ treatment during extinction. To test whether the noncycling groups (Experiment 2) exhibit similar extinction patterns to those of the cycling groups (Experiment 1) and to confirm the extent to which daily $\mathrm{E}_{2}$ enhances extinction of a CPP, rats treated with $\mathrm{E}_{2}$ on day 1 of extinction continued during extinction with daily injections of $\mathrm{E}_{2}$, whereas rats treated with vehicle on day 1 of extinction continued with daily vehicle injections. As in Experiment 1, we found that daily $\mathrm{E}_{2}$ treatment augmented cocaine seeking before rapidly enhancing its extinction (Fig. 4). ANOVA revealed a significant three-way interaction (Group $\times$ Chamber $\times$ Extinction Trial, $\left.F_{(28,588)}=1.80, P=0.008\right)$ and post hoc tests confirmed that $\mathrm{E}_{2}$-treated rats exhibited a consistent preference for the cocaine-paired chamber on extinction trials $2-6$ that was significantly higher than that of vehicle-treated rats on trials 4 and 5 ( $P$ 's $<0.05)$. Importantly, this CPP rapidly extinguished and was no longer evident by trial 7 (Ps $>0.05)$. Without $\mathrm{E}_{2}$ treatment, however, the vehicle group exhibited a marked deficit in extinction learning across trials (Fig. 4). Post hoc tests confirmed this observed deficit, as these animals exhibited an inconsistent CPP
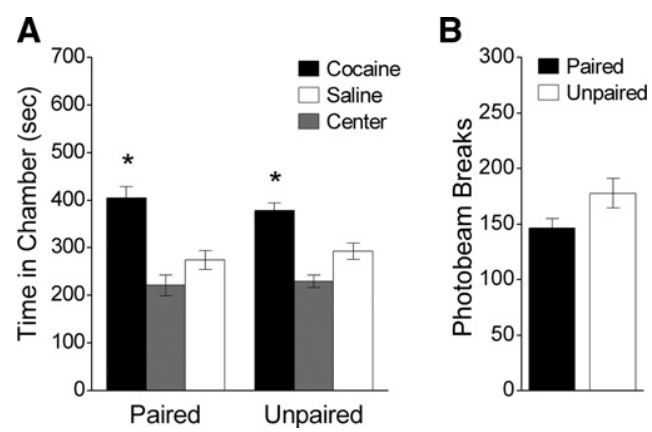

Figure 1. Paired and unpaired $E_{2}$ treatment during conditioning did not affect initial CPP expression. (A) $\mathrm{E}_{2}$ administered $1 \mathrm{~h}$ before (Paired) or during the $2 \mathrm{~d}$ between (Unpaired) conditioning trials resulted in a similar preference for the cocaine-paired chamber compared with either the saline-paired or center chambers. $(B) E_{2}$ treatment had no effect on locomotor activity, as measured by photobeam breaks, when administered prior to a CPP trial regardless of $E_{2}$ treatment during conditioning. $\left.{ }^{*}\right) P<$ 0.05 relative to the saline-paired and center chambers. 


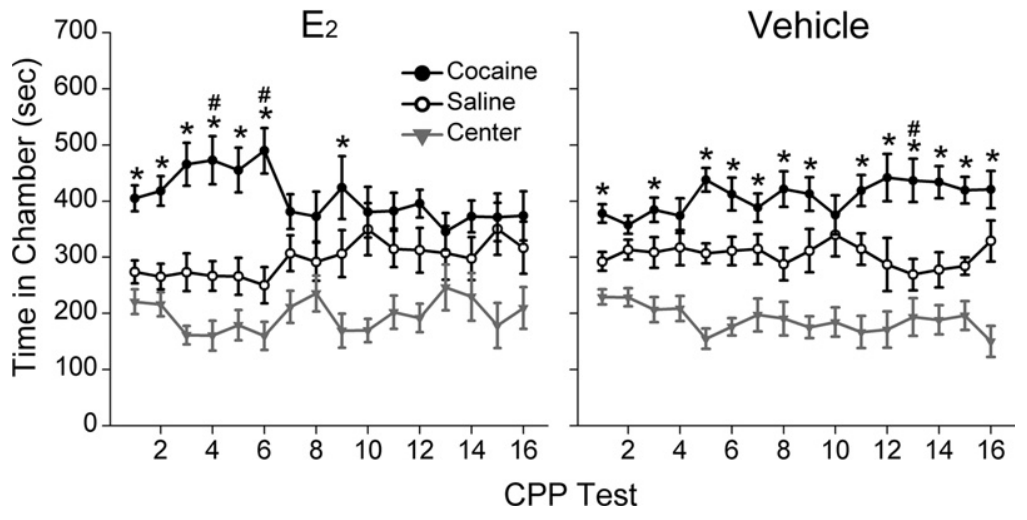

Figure 2. $E_{2}$-enhanced expression and extinction of cocaine seeking. Ovariectomized rats injected daily with $E_{2}(0.2 \mathrm{mg} / \mathrm{kg}$, i.p.) during extinction initially expressed a larger cocaine-induced CPP than vehicle-treated rats, but this extinguished more rapidly than in vehicle-treated rats. Vehicle-treated rats initially expressed a weaker CPP and then exhibited a pronounced deficit in extinction learning that led to a larger CPP in later trials. $\left(^{*}\right) P<0.05$, Cocaine vs. Saline; $\left(^{\# *}\right) P<$ $0.05, E_{2}$ vs. Vehicle.

during early trials that grew more consistent as extinction training continued $\left(P^{\prime} \mathrm{s}<0.05\right)$. Indeed, the CPP was significantly larger than the extinguished preference of their $\mathrm{E}_{2}$-treated counterparts on trials 9 and $16\left(P^{\prime} \mathrm{s}<0.05\right)$. Repeated testing revealed that the vehicle-treated rats failed to extinguish drug seeking across 36 daily trials, and the magnitude of the CPP increased across trials (Fig. 4). ANOVA revealed a significant two-way interaction $\left(\right.$ Chamber $\times$ Extinction Trial, $\left.F_{(70,770)}=1.43, P=0.015\right)$ and post hoc tests confirmed that vehicle-treated rats continued to express a significant cocaine-induced CPP on trials $17-36\left(P^{\prime} \mathrm{s}<0.05\right)$. Together, these data indicate that $\mathrm{E}_{2}$ is sufficient to prevent perseverative cocaine seeking in ovariectomized female rats, and that a lack of $\mathrm{E}_{2}$ replacement prevents extinction learning in this paradigm altogether.

\section{$E_{2}$ rescues a persistent deficit in extinction of cocaine seeking}

Perseveration of drug seeking is a hallmark of addiction (American Psychiatric Association, 2000), and our data show that without $\mathrm{E}_{2}$ replacement, ovariectomized female rats persistently seek out the cocaine-paired chamber in spite of 25 additional extinction trials. Whether $\mathrm{E}_{2}$ would facilitate extinction in these perseverating rats, however, remained unknown. Thus, we asked whether $\mathrm{E}_{2}$ treatment could rescue extinction learning in these rats. Perseverating rats were divided into two groups receiving either vehicle or $\mathrm{E}_{2} 1 \mathrm{~h}$ before further extinction training. We found that daily $\mathrm{E}_{2}$ treatment rescued extinction learning within seven additional extinction trials (trials 37-43), even after 5 wk of perseverative drug seeking (Fig. 5). ANOVA revealed a significant Chamber $\times$ Trial interaction $\left(F_{(2,6)}=9.93, P=0.013\right)$ between trial 36 (last trial without $\mathrm{E}_{2}$ ) and the terminal trial 43 (last trial with $E_{2}$ ) for rats injected with $E_{2}$. Post hoc tests for $E_{2}$-treated rats confirmed that the cocaine CPP on day 36 was no longer significant by trial 43 ; moreover, the amount of time spent on the cocainepaired side on trial 36 was significantly greater than that of trial $43\left(P^{\prime} \mathrm{s}<0.05\right)$. In contrast, ANOVA revealed no difference in the expression of CPP of vehicle-treated rats between trials 36 and $43\left(F_{(2,6)}=0.62, P=0.57\right)$ (Fig. 5). Indeed, there was a significant Chamber effect on trial $43\left(F_{(2,6)}=7.36, P<0.024\right)$, and post hoc tests confirmed that vehicle-treated rats continued to spend significantly more time in the cocaine-paired chamber than either the saline-paired or center chambers $\left(P^{\prime} \mathrm{s}<0.05\right)$. Taken together, these results demonstrate that $\mathrm{E}_{2}$ can rescue the capacity to extinguish drug seeking.

\section{Discussion}

We found that $\mathrm{E}_{2}$ facilitates extinction of cocaine seeking in ovariectomized female rats independently of its wellcharacterized enhancement of cocaine's unconditioned hedonic effects (Becker and $\mathrm{Hu}$ 2008). The magnitude of the initial CPP was identical regardless of whether $\mathrm{E}_{2}$ was explicitly paired or unpaired with cocaine (Experiment 1 ) or administered daily (Experiment 2) during conditioning. Moreover, acute $\mathrm{E}_{2}$ treatment just prior to the first extinction trial had no effect on the magnitude of CPP expression. Therefore, the $\mathrm{E}_{2}$-enhanced expression of cocaine seeking observed during extinction is not likely due to $\mathrm{E}_{2}$-mediated enhancements of either cocaine reward or learning during conditioning. Rather, our results indicate that $\mathrm{E}_{2}$ treatment during extinction training leads to both greater expression and faster extinction through a mnemonic mechanism. Moreover, without $\mathrm{E}_{2}$ replacement, ovariectomized female rats fail to suppress cocaine-seeking behavior under extinction conditions. Remarkably, this extinction learning deficit can be rescued by $\mathrm{E}_{2}$ treatment even after $5 \mathrm{wk}$ of perseverative cocaine seeking. As such, daily $\mathrm{E}_{2}$ treatment is sufficient to enhance the cognitive processes necessary for extinction learning to proceed. These data suggest that although $\mathrm{E}_{2}$ promotes cocaine intake in female rats self-administering cocaine (Zhao and Becker 2010), subsequent treatment with this hormone also enhances the learning required to suppress cocaine seeking during extinction.

The finding that $\mathrm{E}_{2}$ enhances extinction of cocaine seeking in females is consistent with previous studies showing that $E_{2}$ enhances performance on a wide range of cognitive tasks, including extinction learning in other paradigms (Milad et al. 2009; Phan et al. 2012; Zhao et al. 2012). $E_{2}$ replacement or elevated $E_{2}$ levels are associated with improved object and social recognition (Gresack and Frick 2006a; Phan et al. 2012), spatial reference memory in a water maze (Gresack and Frick 2006a), and extinction of fear in female rats and humans (Milad et al. 2009, 2010).
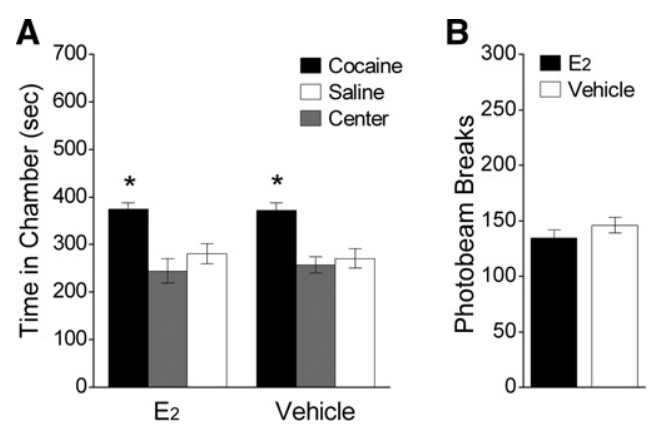

Figure 3. Acute $E_{2}$ did not affect expression of a cocaine-induced CPP. (A) $\mathrm{E}_{2}$ - and vehicle-treated rats both exhibited a similar preference for the cocaine-paired chamber compared with either the saline-paired or center chambers. $(B) \mathrm{E}_{2}$ injection had no effect on locomotor activity, as measured by photobeam breaks, when administered prior to a CPP trial. (*) $P<0.05$ relative to the saline-paired and center chambers. 

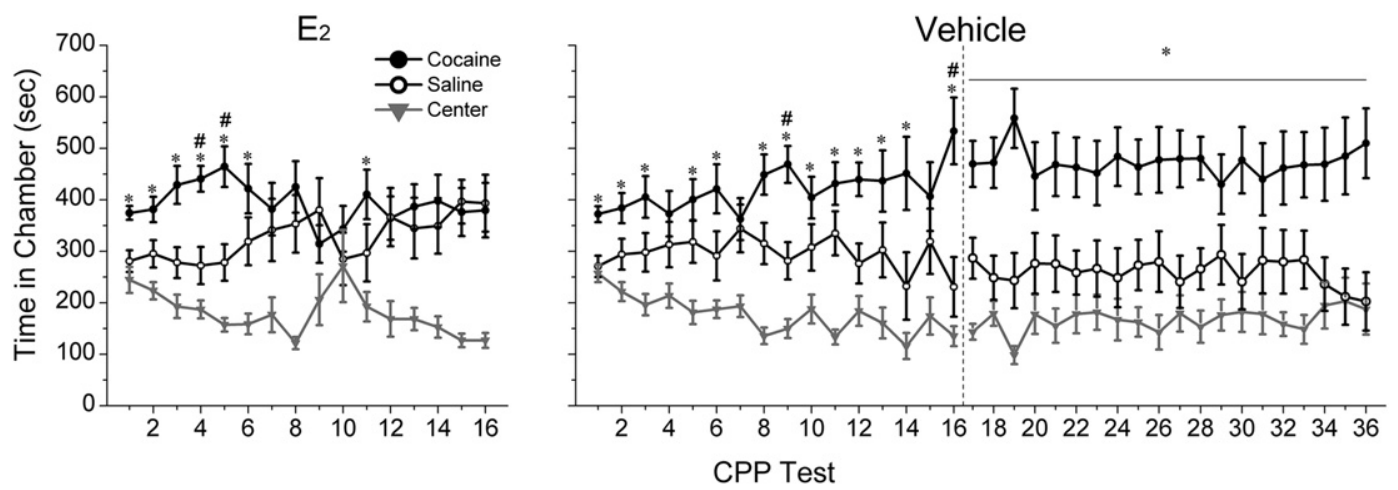

Figure 4. $\mathrm{E}_{2}$ administered $1 \mathrm{~h}$ before daily extinction trials enhanced expression and extinction of a cocaine CPP in rats that were maintained on $\mathrm{E}_{2}$ during conditioning. Ovariectomized rats injected daily with $\mathrm{E}_{2}$ during extinction initially expressed a larger cocaine-induced CPP than vehicle-treated rats, but extinguished more rapidly than in vehicle-treated rats. Vehicle-treated rats initially expressed a weaker CPP and then exhibited a pronounced deficit in extinction learning that led to larger CPP in later trials. Vehicle-treated rats failed to exinguish drug-seeking behavior in 36 trials. $(*) P<$ 0.05 , Cocaine vs. Saline; $\left({ }^{\# *}\right) P<0.05, E_{2}$ vs. Vehicle on the same day.

Similarly, low estrogen levels predict resistance to extinction of fear-potentiated startle in women diagnosed with post-traumatic stress syndrome (Glover et al. 2012), and recent evidence shows that low levels of $E_{2}$ in both rats and humans leads to resistance to extinction of conditioned fear (Graham and Milad 2013). Extinction depends on new learning that suppresses the expression of the original memory (Bouton 2004). Therefore, $\mathrm{E}_{2}$ could enhance extinction of cocaine seeking by bolstering acquisition, retrieval, and/or consolidation of the new extinction memory or, perhaps, interfering with reconsolidation of the former drug associations (Torregrossa and Taylor 2012). The latter is unlikely because $\mathrm{E}_{2}$ would have also interfered with reconsolidation of extinction and our design employed repeated and prolonged exposure to the context, which favors the formation of extinction memories (Mamiya et al. 2009). Moreover, there is substantial evidence that $\mathrm{E}_{2}$ treatment enhances memory consolidation in other learning paradigms (Packard and Teather 1997; Gresack and Frick 2006a), and emerging evidence that cognitive enhancers administered during the consolidation window can facilitate extinction of cocaine (Botreau et al. 2006; Paolone et al. 2009) or amphetamine CPP (Schroeder and Packard 2003). Although the mnemonic and neural mechanisms underlying $\mathrm{E}_{2}$-induced enhancement of extinction remain unknown, the present experiments are the first to demonstrate that $\mathrm{E}_{2}$ facilitates extinction of cocaine seeking in female rats.

Our findings suggest that $\mathrm{E}_{2}$ is required for females to extinguish cocaine seeking. Ovariectomized female rats failed to extinguish for over a month, but extinction in these rats could be rescued with $\mathrm{E}_{2}$ replacement. The observed perseverative drug seeking was unexpected, and indicative of the necessity of $\mathrm{E}_{2}$ for extinction. The fact that $E_{2}$ rescues these extinction deficits suggests that $E_{2}$ enhances synaptic plasticity associated with extinction learning. Estrogen receptors $\alpha$ and $\beta$ are expressed in the medial prefrontal cortex, amygdala, and hippocampus (Shughrue et al. 1997; Ostlund et al. 2003), structures that mediate extinction learning and consolidation (Quirk and Mueller 2008). $\mathrm{E}_{2}$ stimulates intracellular signaling cascades, growth factor induction, synaptogenesis, and protein synthesis (Spencer et al. 2008; Frick 2012). Importantly, there is a synergistic overlap between the effects of $E_{2}$ and synaptic plasticity associated with extinction learning. For example, $\mathrm{E}_{2}$ increases activation of mitogen-activated protein kinase (MAPK) cascades during memory consolidation (Fernandez et al. 2008), and MAPK signaling is required for extinction (Hugues et al. 2004). Thus, $\mathrm{E}_{2}$ may promote extinction through stimulation of MAPK cascades. Similarly, levels of brain- derived neurotrophic factor are increased following both $\mathrm{E}_{2}$ administration (Luine and Frankfurt 2012) and successful extinction (Peters et al. 2010). Collectively, these findings suggest that $\mathrm{E}_{2}$ acts to strengthen synaptic plasticity associated with extinction learning. As such, the absence of $\mathrm{E}_{2}$ could suppress synaptic plasticity, thereby impairing extinction.

Our finding that $\mathrm{E}_{2}$ transiently enhanced expression of cocaine seeking is congruent with the vast majority of literature describing the enhanced response to cocaine exhibited by $\mathrm{E}_{2}$-treated female rats. Female rats exhibit enhanced responding to psychostimulants in multiple paradigms in a manner both dependent and independent of ovarian sex hormones (Hu et al. 2004; Jackson et al. 2006). In ovariectomized rats, $\mathrm{E}_{2}$ enhances the sensitization of cocaine-induced locomotor behavior and CPP (Segarra et al. 2010), self-administration of cocaine on both fixed and progressive ratio schedules of reinforcement (Lynch and Taylor 2005; Zhao and Becker 2010), and preference for cocaine over food reinforcement in a discrete trials procedure (Kerstetter and Kippin 2011), and lowers thresholds for electrical brain stimulation of the ventral tegmental area (Galankin et al. 2010). Thus, $\mathrm{E}_{2}$-enhanced expression of CPP could be interpreted as further evidence in females of "enhanced abuse liability to cocaine," yet this interpretation is at odds with the finding that $\mathrm{E}_{2}$ also enhanced extinction of drug seeking. In fact, because $E_{2}$ augmented CPP expression only after four extinction trials, the data point

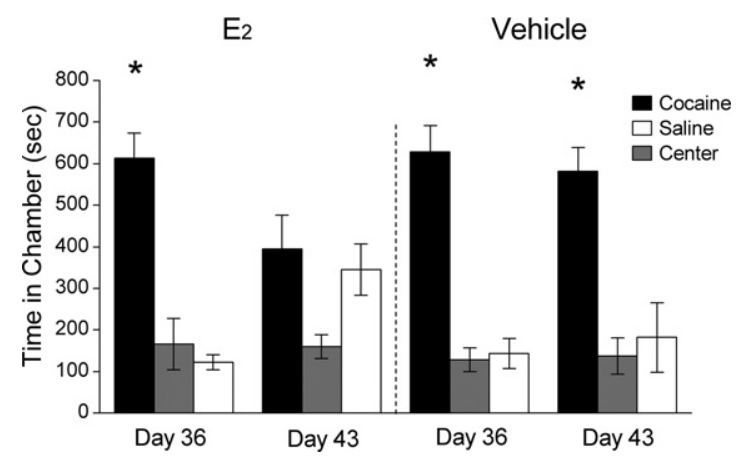

Figure 5. $E_{2}$ treatment rescues an extinction learning deficit in ovariectomized rats that perseverate on cocaine seeking. A cocaine-induced CPP that persisted for $5 \mathrm{wk}$ was abolished by $7 \mathrm{~d}$ of $\mathrm{E}_{2}$ administration with extinction training. Vehicle-treated rats, however, continued to express a cocaine CPP. $\left(^{*}\right) P<0.05$ relative to the saline-paired and center chambers. 
toward an alternative explanation, specifically that a common neural and mnemonic mechanism mediates both enhanced expression and extinction. Because $\mathrm{E}_{2}$ enhances memory in a variety of paradigms, $\mathrm{E}_{2}$ may act to enhance working memory and/or retrieval of the original cocaine association, thereby augmenting the incentive salience of the cocaine-associated context and enhancing expression of the CPP. The same $E_{2}$-mediated cognitive enhancement, then, would also enhance extinction learning and lead to more rapid extinction of cocaine seeking. Neurobiologically, both enhanced expression and extinction would likely be influenced by $\mathrm{E}_{2}$ modulation of mesocorticolimbic dopamine (Bazzett and Becker 1994; Wyvell and Berridge 2001; Jacobs and D'Esposito 2011) or norepinephrine signaling (Mueller et al. 2008; Mueller and Cahill 2010; Otis and Mueller 2011). Thus, it is conceivable that previous reports demonstrating enhanced expression of cocaine-induced CPP assign too much importance to estrogen's undisputed enhancement of cocaine reward with little attention paid to the cognitive enhancements mediated by $\mathrm{E}_{2}$.

The present findings have clear implications for basic and clinical research, and for clinical treatment of women addicted to cocaine. Estrogens are key hormones that regulate the response to cocaine in both female rats and humans (Segarra et al. 2010). Changes in estrogen levels in cycling females may account for the apparent greater severity of cocaine addiction, or faster transition from use to abuse, relative to that of men (Becker et al. 2012). Nevertheless, more men than women initiate illicit drug use ( $55.1 \%$ vs. $44 \%$; and for cocaine, $18.1 \%$ vs. $11.4 \%$ ), which may account for the higher rate overall of drug abuse among men $(3.6 \%$ vs. 2.0\%; SAMHSA 2010). These findings suggest a differential path to abuse for men and women (for review, see Becker et al. 2012) or, alternatively, reflect the greater propensity for women to remain abstinent following treatment for drug abuse (Weiss et al. 1997). Our finding that $E_{2}$ treatment enhanced extinction of cocaine seeking even in ovariectomized rats that were perseverating for up to $5 \mathrm{wk}$ suggests a potentially vital role for $\mathrm{E}_{2}$ in the recovery from cocaine abuse. The importance of $\mathrm{E}_{2}$ is underscored by our finding that female rats in the absence of $\mathrm{E}_{2}$ failed to suppress cocaine seeking during extinction, and may explain why gonadally intact female rats in estrus (low $\mathrm{E}_{2}$ levels) are more resistant to extinction of drug seeking than are male rats (Kerstetter et al. 2008; Anker et al. 2010). Therefore, low $E_{2}$ levels may increase the risk of relapse in some women, and this risk may be exacerbated by cocaine-induced menstrual cycle disorders (Mello and Mendelson 1997). Because $\mathrm{E}_{2}$ levels may predict individual differences in response to treatment, our data suggest a potential benefit of routine assessment of hormonal status as part of treatment of cocaine addiction in women. Moreover, our findings suggest a need to maintain optimal levels of $E_{2}$ to enhance therapeutic outcome in cocaine-addicted women.

\section{Materials and Methods}

\section{Subjects and surgery}

Female Long-Evans rats (Harlan Laboratories, 175-200 g) were individually housed in clear plastic cages. Rats were maintained on a 14-h light /10-h dark cycle (lights on at $07.00 \mathrm{~h}$ ), and had unlimited access to water and standard laboratory rat chow (Teklad, Harlan Laboratories). Rats were weighed and handled daily. All experimental protocols were approved by the Institutional Animal Care and Use Committee at the University of WisconsinMilwaukee in accordance with National Institutes of Health guidelines.

Rats were handled for a minimum of $3 \mathrm{~d}$ prior to surgery. They were then anesthetized with a mixture of ketamine/xylazine (90 mg/kg/10.5 mg/kg, i.p.), and underwent bilateral ovariecto- my using a dorsal approach (Frick et al. 2004). Through a single incision along the spine, the ovary was isolated, the tip of the uterus was clamped and ligated, and the ovary was removed with a scalpel. The remaining tissue was returned to the abdomen, the procedure repeated on the other ovary, and the incision closed with sterile silk suture and wound clips. Following surgery, rats were given an antibiotic (penicillin G procaine, 75,000 units in $0.25 \mathrm{~mL}$ ) and an analgesic (carprofen, $5.0 \mathrm{mg}$ in $0.1 \mathrm{~mL}$ ) subcutaneously, and were given $7 \mathrm{~d}$ to recover.

\section{Drugs}

Cocaine $\mathrm{HCl}$ (National Institute on Drug Abuse) was dissolved in sterile $0.9 \%$ saline $(10 \mathrm{mg} / \mathrm{mL})$, and administered at a dose of $10 \mathrm{mg} / \mathrm{kg}$, i.p. To ensure that $\mathrm{E}_{2}$ levels would not build up over time from repeated infusions, we used a water-soluble form of $\mathrm{E}_{2}$ dissolved in 2-hydroxypropyl- $\beta$-cyclodextrin (HBC) that is metabolized within $24 \mathrm{~h}$ (Pitha and Pitha 1985). The HBC vehicle and HBC-encapsulated $\mathrm{E}_{2}$ (Sigma Aldrich) were dissolved in sterile $0.9 \%$ saline $(0.2 \mathrm{mg} / \mathrm{mL})$ and injected i.p. $1 \mathrm{~h}$ before testing at a dose of $0.2 \mathrm{mg} / \mathrm{kg}$. This dose produces levels of $E_{2}$ in the physiological range (Gresack and Frick 2006b). Post-training i.p. injection of this dose of $\mathrm{HBC}$-encapsulated $\mathrm{E}_{2}$ enhances spatial memory in the water maze in ovariectomized rats (Packard and Teather 1997) and mice (Gresack and Frick 2006a) and object recognition in ovariectomized mice (Gresack and Frick 2006a).

\section{Conditioning and testing}

Conditioning and testing were conducted as described previously (Otis and Mueller 2011). Briefly, a three-chamber apparatus was used in which two larger conditioning chambers were separated by a smaller center chamber. Baseline preferences were determined by placing the rats into the center chamber with free access to the entire apparatus for $15 \mathrm{~min}$. Rats spent less time in the center chamber before conditioning than in either of the larger conditioning chambers $\left(F_{(2,94)}=62.8, P<0.001\right.$; post hoc $P^{\prime}$ s $<$ 0.001 ) and an equivalent amount of time was spent in the conditioning chambers $(P>0.05)$. Therefore, an unbiased procedure was used. Rats were randomly assigned to associate one large chamber with cocaine and the other with saline in a counterbalanced fashion over four conditioning trials. Rats were injected immediately before each 20 -min conditioning session and confined to their respective chambers. For extinction training, rats were placed into the center chamber and allowed free access to the entire apparatus for $15 \mathrm{~min}$. A CPP was determined when significantly more time was spent in the previously cocaine-paired chamber than in the saline-paired chamber.

\section{Hormonal treatment and experimental design}

\section{Experiment 1}

Rats were maintained on an experimenter-controlled, repeating 4-d treatment cycle consisting of $2 \mathrm{~d}$ of $\mathrm{E}_{2}$ followed by $2 \mathrm{~d}$ of HBC vehicle (see Table 1). Conditioning trials were either paired (Paired, $n=11$ ) or explicitly unpaired (Unpaired, $n=12$ ) with $\mathrm{E}_{2}$ over $16 \mathrm{~d}$, resulting in four pairings with cocaine and four with saline. After conditioning, rats were given $4 \mathrm{~d}$ with no hormone injections before CPP testing. On the first CPP test trial, both groups were injected with $\mathrm{E}_{2}$ and tested for a cocaine-induced CPP. For the remainder of the daily extinction trials, rats received either $\mathrm{E}_{2}(n=11)$ or HBC vehicle $(n=12)$.

\section{Experiment 2}

Rats were maintained on daily $\mathrm{E}_{2}$ treatment throughout the conditioning phase (Table 1). Conditioning trials were conducted daily over $8 \mathrm{~d}$, resulting in four pairings with cocaine and four with saline. After conditioning, rats were given $4 \mathrm{~d}$ with no hormone injections before CPP testing. Rats were injected with $\mathrm{E}_{2}(n=11)$ or HBC vehicle (Vehicle, $n=12$ ) prior to each CPP test trial. These conditions were maintained for the remainder of extinction 
testing through trial 36 . To determine whether $\mathrm{E}_{2}$ treatment could rescue extinction learning in perseverating rats, the rats treated with $\mathrm{HBC}$ vehicle during extinction were divided into two groups receiving either vehicle $(n=4)$ or $\mathrm{E}_{2}(n=4) 1 \mathrm{~h}$ before further extinction training. These rats received either daily $\mathrm{E}_{2}$ treatment or vehicle for an additional seven extinction trials (trials 37-43).

\section{Data analysis}

Drug seeking during single or across multiple CPP trials was analyzed by comparing time spent in the previously cocaine-paired, saline-paired, and center chambers using multivariate mixed model and repeated measures ANOVA. When appropriate main and interaction effects were detected, Fisher's LSD post hoc tests were used to make pairwise comparisons. All data were analyzed using Statistica 64 (Statsoft, Inc.).

\section{Acknowledgments}

This research was supported by DA027870, University of Wisconsin-Milwaukee Research Growth Initiative to D.M., and University of Wisconsin-Milwaukee College of Letters \& Science funding to K.M.F. We thank Patrick Reilly and Carolynn Rafa Todd for technical assistance.

\section{References}

American Psychiatric Association. 2000. Diagnostic and Statistical Manual of Mental Disorders (DSM-IV-TR), 4th ed, text revision. Arlington, VA. doi: 10.1176/appi.books.9780890423349.

Anker JJ, Zlebnik NE, Carroll ME. 2010. Differential effects of allopregnanolone on the escalation of cocaine self-administration and sucrose intake in female rats. Psychopharmacology (Berl) 212: 419-429.

Bazzett TJ, Becker JB. 1994. Sex differences in the rapid and acute effects of estrogen on striatal D2 dopamine receptor binding. Brain Res 637: $163-172$.

Becker JB, Hu M. 2008. Sex differences in drug abuse. Front Neuroendocrinol 29: $36-47$.

Becker JB, Perry AN, Westenbroek C. 2012. Sex differences in the neural mechanisms mediating addiction: A new synthesis and hypothesis. Biol Sex Differ 3: 14.

Botreau F, Paolone G, Stewart J. 2006. D-Cycloserine facilitates extinction of a cocaine-induced conditioned place preference. Behav Brain Res 172: $173-178$.

Bouton ME. 2004. Context and behavioral processes in extinction. Learn Mem 11: 485-494.

Chen K, Kandel D. 2002. Relationship between extent of cocaine use and dependence among adolescents and adults in the United States. Drug Alcohol Depend 68: 65-85.

Daniel JM. 2006. Effects of oestrogen on cognition: What have we learned from basic research? J Neuroendocrinol 18: 787-795.

Evans SM. 2007. The role of estradiol and progesterone in modulating the subjective effects of stimulants in humans. Exp Clin Psychopharmacol 15: $418-426$

Febo M, Jimenez-Rivera CA, Segarra AC. 2002. Estrogen and opioids interact to modulate the locomotor response to cocaine in the female rat. Brain Res 943: 151-161.

Fernandez SM, Lewis MC, Pechenino AS, Harburger LL, Orr PT, Gresack JE Schafe GE, Frick KM. 2008. Estradiol-induced enhancement of object memory consolidation involves hippocampal extracellular signal-regulated kinase activation and membrane-bound estrogen receptors. J Neurosci 28: 8660-8667.

Frick KM. 2012. Building a better hormone therapy? How understanding the rapid effects of sex steroid hormones could lead to new therapeutics for age-related memory decline. Behav Neurosci 126: 29-53.

Frick KM, Fernandez SM, Bennett JC, Prange-Kiel J, MacLusky NJ, Leranth C. 2004. Behavioral training interferes with the ability of gonadal hormones to increase CA1 spine synapse density in ovariectomized female rats. Eur I Neurosci 19: 3026-3032.

Galankin T, Shekunova E, Zvartau E. 2010. Estradiol lowers intracranial self-stimulation thresholds and enhances cocaine facilitation of intracranial self-stimulation in rats. Horm Behav 58: 827-834.

Gallop RJ, Crits-Christoph P, Ten Have TR, Barber JP, Frank A, Griffin ML, Thase ME. 2007. Differential transitions between cocaine use and abstinence for men and women. J Consult Clin Psychol 75: 95-103.
Glover EM, Jovanovic T, Mercer KB, Kerley K, Bradley B, Ressler KJ, Norrholm SD. 2012. Estrogen levels are associated with extinction deficits in women with posttraumatic stress disorder. Biol Psychiatry 72: $19-24$.

Graham BM, Milad MR. 2013. Blockade of estrogen by hormonal contraceptives impairs fear extinction in female rats and women. Biol Psychiatry 73: 371-378.

Gresack JE, Frick KM. 2006a. Post-training estrogen enhances spatial and object memory consolidation in female mice. Pharmacol Biochem Behav 84: $112-119$

Gresack JE, Frick KM. 2006b. Effects of continuous and intermittent estrogen treatments on memory in aging female mice. Brain Res 1115: $135-147$.

Hu M, Crombag HS, Robinson TE, Becker JB. 2004. Biological basis of sex differences in the propensity to self-administer cocaine. Neuropsychopharmacology 29: 81-85.

Hugues S, Deschaux O, Garcia R. 2004. Postextinction infusion of a mitogen-activated protein kinase inhibitor into the medial prefrontal cortex impairs memory of the extinction of conditioned fear. Learn Mem 11: 540-543.

Jackson LR, Robinson TE, Becker JB. 2006. Sex differences and hormonal influences on acquisition of cocaine self-administration in rats. Neuropsychopharmacology 31: 129-138.

Jacobs E, D'Esposito M. 2011. Estrogen shapes dopamine-dependent cognitive processes: Implications for women's health. J Neurosci 31: $5286-5293$.

Kerstetter KA, Kippin TE. 2011. Impact of sex and gonadal hormones on cocaine and food reinforcement paradigms. I Addict Res Ther S4: 2963.

Kerstetter KA, Aguilar VR, Parrish AB, Kippin TE. 2008. Protracted time-dependent increases in cocaine-seeking behavior during cocaine withdrawal in female relative to male rats. Psychopharmacology (Berl) 198: $63-75$.

Larson EB, Anker JJ, Gliddon LA, Fons KS, Carroll ME. 2007. Effects of estrogen and progesterone on the escalation of cocaine self-administration in female rats during extended access. Exp Clin Psychopharmacol 15: $461-471$.

Luine V, Frankfurt M. 2012. Interactions between estradiol, BDNF and dendritic spines in promoting memory. Neuroscience doi: 10.1016/ j.neuroscience.2012.10.019.

Lynch WJ, Taylor JR. 2005. Decreased motivation following cocaine self-administration under extended access conditions: Effects of sex and ovarian hormones. Neuropsychopharmacology 30: 927-935.

Mamiya N, Fukushima H, Suzuki A, Matsuyama Z, Homma S, Frankland PW, Kida S. 2009. Brain region-specific gene expression activation required for reconsolidation and extinction of contextual fear memory. I Neurosci 29: 402-413.

McCance-Katz EF, Carroll KM, Rounsaville BJ. 1999. Gender differences in treatment-seeking cocaine abusers-implications for treatment and prognosis. Am J Addict 8: 300-311.

Mello NK, Mendelson JH. 1997. Cocaine's effects on neuroendocrine systems: Clinical and preclinical studies. Pharmacol Biochem Behav 57: $571-599$.

Milad MR, Igoe SA, Lebron-Milad K, Novales JE. 2009. Estrous cycle phase and gonadal hormones influence conditioned fear extinction. Neuroscience 164: 887-895.

Milad MR, Zeidan MA, Contero A, Pitman RK, Klibanski A, Rauch SL, Goldstein JM. 2010. The influence of gonadal hormones on conditioned fear extinction in healthy humans. Neuroscience 168: $652-658$.

Mueller D, Cahill SP. 2010. Noradrenergic modulation of extinction learning and exposure therapy. Behav Brain Res 208: 1-11.

Mueller D, Porter JT, Quirk GJ. 2008. Noradrenergic signaling in infralimbic cortex increases cell excitability and strengthens memory for fear extinction. J Neurosci 28: 369-375.

Ostlund H, Keller E, Hurd YL. 2003. Estrogen receptor gene expression in relation to neuropsychiatric disorders. Ann N Y Acad Sci 1007: $54-63$.

Otis JM, Mueller D. 2011. Inhibition of $\beta$-adrenergic receptors induces a persistent deficit in retrieval of a cocaine-associated memory providing protection against reinstatement. Neuropsychopharmacology 36: 1912-1920.

Packard MG, Teather LA. 1997. Posttraining estradiol injections enhance memory in ovariectomized rats: Cholinergic blockade and synergism. Neurobiol Learn Mem 68: 172-188.

Paolone G, Botreau F, Stewart J. 2009. The facilitative effects of D-cycloserine on extinction of a cocaine-induced conditioned place preference can be long lasting and resistant to reinstatement. Psychopharmacology (Berl) 202: 403-409.

Peters J, Dieppa-Perea LM, Melendez LM, Quirk GJ. 2010. Induction of fear extinction with hippocampal-infralimbic BDNF. Science 328: $1288-1290$. 
Phan A, Gabor CS, Favaro KJ, Kaschack S, Armstrong JN, Maclusky NJ, Choleris E. 2012. Low doses of $17 \beta$-estradiol rapidly improve learning and increase hippocampal dendritic spines. Neuropsychopharmacology 37: 2299-2309.

Pitha J, Pitha J. 1985. Amorphous water-soluble derivatives of cyclodextrins: Nontoxic dissolution enhancing excipients. J Pharm Sci 74: $987-990$.

Potenza MN, Hong KI, Lacadie CM, Fulbright RK, Tuit KL, Sinha R. 2012. Neural correlates of stress-induced and cue-induced drug craving: Influences of sex and cocaine dependence. Am J Psychiatry 169: 406-414.

Quirk GJ, Mueller D. 2008. Neural mechanisms of extinction learning and retrieval. Neuropsychopharmacology 33: 56-72.

Robbins SJ, Ehrman RN, Childress AR, O'Brien CP. 1999. Comparing levels of cocaine cue reactivity in male and female outpatients. Drug Alcohol Depend 53: 223-230.

SAMHSA. 2010. National Survey on Drug Use and Health. Substance Abuse and Mental Health Services Administration: Substance Abuse and Mental Health Data Archive http://www.icpsr.umich.edu/ icpsrweb/SAMHDA/studies/32722, doi: 10.3886/ICPSR32722.v3. ICPSR/University of Michigan Institute for Social Research, Ann Arbor, MI.

Schroeder JP, Packard MG. 2003. Systemic or intra-amygdala injections of glucose facilitate memory consolidation for extinction of drug-induced conditioned reward. Eur J Neurosci 17: 1482-1488.

Segarra AC, Agosto-Rivera JL, Febo M, Lugo-Escobar N, Menendez-Delmestre R, Puig-Ramos A, Torres-Diaz YM. 2010. Estradiol: A key biological substrate mediating the response to cocaine in female rats. Horm Behav 58: 33-43.
Shughrue PJ, Lane MV, Merchenthaler I. 1997. Comparative distribution of estrogen receptor- $\alpha$ and $-\beta$ mRNA in the rat central nervous system. $J$ Comp Neurol 388: 507-525.

Spencer JL, Waters EM, Romeo RD, Wood GE, Milner TA, McEwen BS. 2008. Uncovering the mechanisms of estrogen effects on hippocampal function. Front Neuroendocrinol 29: 219-237.

Torregrossa MM, Taylor JR. 2012. Learning to forget: Manipulating extinction and reconsolidation processes to treat addiction. Psychopharmacology (Berl) doi: 10.1007/ s00213-012-2750-9.

Waldrop AE, Price KL, Desantis SM, Simpson AN, Back SE, McRae AL, Spratt EG, Kreek MJ, Brady KT. 2012. Community-dwelling cocainedependent men and women respond differently to social stressors versus cocaine cues. Psychoneuroendocrinology 35: 798-806.

Weiss RD, Martinez-Raga J, Griffin ML, Greenfield SF, Hufford C. 1997. Gender differences in cocaine dependent patients: A 6 month follow-up study. Drug Alcohol Depend 44: 35-40.

Wyvell CL, Berridge KC. 2001. Incentive sensitization by previous amphetamine exposure: Increased cue-triggered "wanting" for sucrose reward. J Neurosci 21: 7831-7840.

Zhao W, Becker JB. 2010. Sensitization enhances acquisition of cocaine self-administration in female rats: Estradiol further enhances cocaine intake after acquisition. Horm Behav 58: 8-12.

Zhao Z, Fan L, Frick KM. 2012. Epigenetic alterations regulate estradiol-induced enhancement of memory consolidation. Proc Natl Acad Sci 107: 5605-5610.

Received January 9, 2013; accepted in revised form March 19, 2013. 


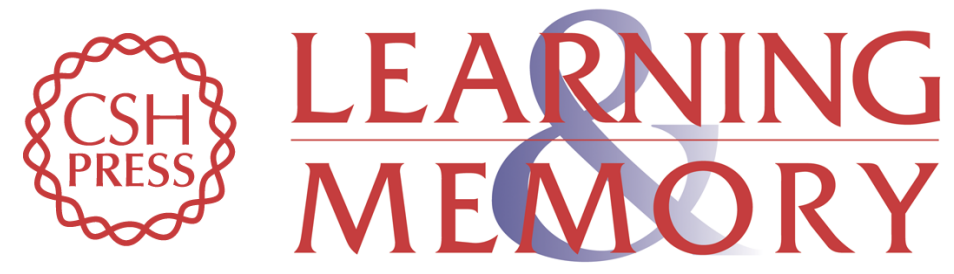

\section{$17 \beta$-Estradiol is necessary for extinction of cocaine seeking in female rats}

Robert C. Twining, Jennifer J. Tuscher, Elizabeth M. Doncheck, et al.

Learn. Mem. 2013, 20:

Access the most recent version at doi:10.1101/Im.030304.113

References This article cites 57 articles, 8 of which can be accessed free at:

http://learnmem.cshlp.org/content/20/6/300.full.html\#ref-list-1

License

Email Alerting Receive free email alerts when new articles cite this article - sign up in the box at the Service top right corner of the article or click here. 